\title{
Mercosur, inserción subalterna y burguesías internas de Argentina y Brasil
}

\author{
Mercosur, subaltern insertion and internal bourgeoisies of Argentina and Brazil
}

\author{
Leonardo Granato*
}

Resumen: Partiendo de una crítica a las visiones hegemónicas sobre integración regional presentes en los campos de la economía y de relaciones internacionales, este artículo reflexiona sobre la trayectoria del Mercosur argumentando acerca de la correspondencia de tal trayectoria con los intereses de sectores más dinámicos de las burguesías internas de Argentina y Brasil. Se señala que, pese al intento de los gobiernos progresistas del siglo XXI en desafiar los cánones integracionistas impuestos por ciertos sectores hegemónicos de las clases dominantes en ambos países, el Mercosur no consiguió escapar de su marca de origen: la inserción externa dependiente. En este orden, se resaltan las limitaciones que la dinámica del capital y la correlación de fuerzas impusieron, en este campo de la integración, a la acción política.

Palabras clave: Mercosur; Inserción Externa; Dependencia; Argentina; Brasil.

\begin{abstract}
Based on a critique of the hegemonic views on regional integration present in the fields of economics and international relations, this article reflects on the Mercosur's trajectory arguing about the correspondence of this trajectory with the interests of more dynamic sectors of the internal bourgeoisies from Argentina and Brazil. We point out that despite the attempt of the progressive governments of the 21 st century to challenge the integrationist canons imposed by certain hegemonic sectors of the dominant classes in both countries, Mercosur did not manage to escape its original goal of a dependent external insertion. In this order, we highlight the limitations that the dynamics of capital and the correlation of forces imposed on political action, in this field of integration.
\end{abstract}

Keywords: Mercosur; External Insertion; Dependency; Argentina; Brazil.

Recibido: 2 diciembre 2018 Aceptado: 13 febrero 2019

\section{Introducción}

A la hora de discutir el estado actual de la integración sudamericana, que tiene entre sus pilares al Mercosur ${ }^{1}$, algunas perspectivas defienden que estaríamos asistiendo a la reconfiguración del modelo de integración emergente de la crisis de las políticas neoliberales, y del período conocido como la "marea rosa" de los años $2000^{2}$. A pesar de reconocer la validez de este argumento, buscamos problematizar, por medio del presente artículo, esta lectura del presente regional preguntándonos en qué medida la

\footnotetext{
* Argentino. Doctor en Economía Política Internacional (Universidade Federal do Rio de Janeiro). Profesor del Programa de Posgrado en Ciencia Política de la Universidade Federal do Rio Grande do Sul. leonardo.granato@,ufrgs.br

${ }^{1}$ Acrónimo de "Mercado Común del Sur".

2 Fabricio Pereira da Silva, "La bajada de la marea rosa en América Latina. Una introducción", Revista de la Red Intercátedras de Historia de América Latina Contemporánea-Segunda Época, 5:8, Córdoba, 2018, 59-66.
} 
reconfiguración del Mercosur del siglo XXI comportó un verdadero cambio en términos de objetivos de inserción externa de las clases dominantes de sus países miembros, principalmente de Argentina y Brasil.

$\mathrm{Al}$ concebir la integración como una política estatal o pública emanada de los aparatos estatales de un grupo de países, aparatos que es donde se procesan y condensan las disputas de clases ${ }^{3}$, buscamos reflexionar sobre la trayectoria del Mercosur argumentando acerca de la correspondencia de tal trayectoria con los intereses de las burguesías internas ${ }^{4}$ de Argentina y Brasil. De forma complementaria, argumentamos que pese al intento de los gobiernos progresistas del nuevo siglo en desafiar los cánones integracionistas impuestos por el accionar de las mencionadas burguesías, el Mercosur no consiguió escapar de su marca de origen: la inserción externa dependiente o subalterna ${ }^{5}$.

El presente artículo está dividido en dos partes. En la primera parte, discutimos cómo las principales vertientes de la teoría económica y de la teoría en relaciones internacionales abordan el concepto de integración regional. En la segunda parte del trabajo, discutimos las bases teóricas para un abordaje crítico de la integración como política estatal y proponemos una lectura del Mercosur a la luz de los intereses de las burguesías internas de Argentina y Brasil, enfatizando las limitaciones vivenciadas por la acción política del siglo XXI al intentar, mediante un nuevo modelo de integración, desafiar el orden establecido.

\section{El estudio de la integración regional en América Latina: discutiendo las visiones hegemónicas}

La integración regional es tradicionalmente abordada por los campos de la economía y de las relaciones internacionales. En el primero de los campos, este tipo de procesos son discutidos, en su dimensión económica, particularmente en el contexto del debate sobre desarrollo. Ya en el ámbito de las

\footnotetext{
3 Adoptamos, en este trabajo, una concepción poulantziana de Estado en tanto parte específica de las relaciones sociales capitalistas; parte específica caracterizada por la dominación, por el poder político. Sea el Estado definido como la estructura jurídico-política de una sociedad dividida en clases, que favorece un equilibrio inestable de compromisos entre dominantes y dominados, sea como la condensación material de una relación contradictoria, nos interesa resaltar aquí el elemento crucial de su materialidad: las contradicciones de clase. Son esas contradicciones que tornan posible el papel organizador del Estado (autonomía), y que a su vez impiden su disolución debido a luchas de fracciones del bloque en el poder, en determinado momento histórico. Nicos Poulantzas, Poder político e classes sociais, São Paulo, Martins Fontes, 1977. Nicos Poulantzas, O Estado, o poder e o socialismo, Rio de Janeiro, Graal, 1980.

${ }^{4} \mathrm{El}$ término burguesía interna es empleado en este trabajo conforme las formulaciones teóricas de Poulantzas al analizar los casos de las burguesías de países como España, Portugal y Grecia. Según este autor, la clase capitalista puede clasificarse en burguesía nacional, burguesía compradora y burguesía interna. El concepto de burguesía nacional se refiere a la fracción del capital de origen doméstico (que posee base acumulación propia), que actúa en defensa del mercado interno y de proyectos de desarrollo industrial, y que puede participar, juntamente con diversos sectores de las clases populares, de frentes antimperialistas. Ya la expresión burguesía compradora (también llamada por la literatura de asociada o integrada) remite a una fracción de clase que no cuenta con base de acumulación propia, actuando como aliados internos del capital financiero internacional. Finalmente, la burguesía interna es aquella fracción que posee una relación de dependencia (financiera y tecnológica) con el capital extranjero, ocasionándole ello dificultades para asumir posiciones antimperialistas, así como para la formación de alianzas con sectores de las clases populares. Esta burguesía interna está vinculada esencialmente a los sectores de la actividad productiva destinada al mercado interno (pudiendo aglutinar también sectores como el bancario o el comercial), y coexiste de manera subordinada a los intereses de la burguesía compradora. Nicos Poulantzas, A crise das ditaduras: Portugal, Espanha e Grécia, Rio de Janeiro, Paz e Terra, 1976.

${ }^{5}$ Con los términos inserción subalterna, subordinada o dependiente nos referimos a aquella estrategia de un país periférico que no busca desafiar los cánones del sistema interestatal capitalista, asimétrico, desigual y jerarquizado, articulado por los intereses y potencias dominantes. Este tipo de inserción, diferentemente de la autónoma, se basa, principalmente, en términos políticos, en la falta de libertad de maniobra para la formulación de políticas de desarrollo (industrialización, generación de conocimiento y de tecnología) que propendan a una alteración de la división internacional del trabajo, y en términos comerciales, en la exportación de bienes intensivos en recursos naturales vinculados a ventajas comparativas (estáticas), en la importación de manufacturas intermedias (con alto contenido tecnológico) que luego son exportadas como bienes finales a los países centrales, y en el fomento de las inversiones extranjeras.
} 
relaciones internacionales, el tema es abordado principalmente, en su dimensión jurídico-institucional, por las perspectivas clásicas liberal y realista. En ambos casos, la mayoría de las explicaciones, dominantes en el campo del saber de la integración, comparten una misma visión liberal de Estado, entendido como un conjunto de instituciones situado fuera y por encima de la sociedad, desempeñando un rol de mediador neutral dotado de capacidad para garantizar, a través de sus decisiones y políticas, el llamado "interés nacional", o "bien común" público.

A diferencia del abordaje liberal, entender al Estado en los términos de autores como Poulantzas nos permite reconocerlo como un elemento complejo, constituido a partir de las contradicciones de clase, rompiendo con los moldes liberales hegemónicos que buscan encubrir que el Estado no actúa sino dentro de ciertos límites históricos que enmarcan lo que es circunstancialmente posible sin comprometer la relación básica social capitalista.

El actual proceso del Mercosur tiene como antecedente, en el ámbito latinoamericano, las experiencias integracionistas de carácter económico que se sucedieron entre las décadas del ' 60 y ' $80^{6}$, que reflejaron la disputa ${ }^{7}$, en el ámbito de la teoría económica, entre aquellos que defendían una política de integración basada en el principio de libre comercio (ortodoxos liberales) y aquellos que buscaban ir más allá, reafirmando la importancia de una solidaridad estratégica con vistas a una modernización industrializadora que propendería al desarrollo en la periferia de la geopolítica mundial, bajo el impulso de la política estatal, siempre en el ámbito capitalista ${ }^{8}$, en consonancia con las bases y puntos de partida del estructuralismo cepalino (heterodoxos keynesianos o estructuralistas) 9 .

En ambos casos, bajo la influencia del paradigma positivista de la racionalidad instrumental y de las vertientes modernizadoras del pensamiento social y político típicos del siglo XX, prevaleció en nuestro medio una perspectiva reduccionista de la integración regional, entendida esta última, en términos económico-comerciales, como una fórmula de mero cálculo, a cargo de las burocracias estatales, y con fundamento en el interés nacional, sin tomar en cuenta las clases sociales y sus luchas, la existencia de conflictos de interés, económicos y de poder, dentro de cada país, y dentro y fuera de la región ${ }^{10}$. Pese a ello, como contrapunto, la tarea de los teóricos de la dependencia de bases marxistas no se trataba tan solo de rechazar la hipótesis del desarrollo como fenómeno supuestamente universal sino de analizar la "situación de dependencia" referente a una dominación interno-externa, alertando que si bien las relaciones de fuerza entre las clases se constituyen a escala nacional, las mismas deben ser pensadas, también, en el plano internacional, en la medida en que las relaciones sociales de producción en el capitalismo tienen un desarrollo a escala global ${ }^{11}$. Las formulaciones de esta vertiente buscaban, también, romper con ese tipo ideal hegemónico de Estado racional, homogéneo y neutro (con funciones de carácter universal y capaz de conciliar los intereses de trabajadores y burgueses industriales),

\footnotetext{
${ }^{6}$ La primera ola del regionalismo latinoamericano es representada por la creación del Mercado Común Centroamericano y de la Asociación Latinoamericana de Libre Comercio (ALALC) en 1960, que en los '80 sería sustituida por la Asociación Latinoamericana de Integración (ALADI), y por el Pacto Andino de 1969.

7 A semejanza de lo ocurrido, según Lanús, en la integración europea, cuya discusión giraba entre los defensores de una "Europamercado" y los de una "Europa-comunidad". Juan Archibaldo Lanús, La integración económica de América Latina, Buenos Aires, Juárez Editor, 1972.

8 Entendemos relevante resaltar que tales perspectivas también fueron convergentes en proyectar al capitalismo como figura inexorable del futuro de la humanidad. Las perspectivas ortodoxa y heterodoxa del desarrollo, en contraste con concepciones críticas que conciben al desarrollo capitalista como una fase históricamente contingente del desarrollo social general, asumen, al fin de cuentas, una misma interpretación cosmogónica de la realidad, la capitalista.

${ }^{9}$ Raúl Prebisch, "El desarrollo económico de América Latina y sus principales problemas. 1948”, Documento Institucional, Santiago, CEPAL, 2012.

10 José Luís Fiori, "Estado e desenvolvimento na América Latina: notas para um novo 'programa de pesquisa", Documento de Trabalho, 286, Brasília, CEPAL Escritório no Brasil, 2013, 4.

11 Ruy Mauro Marini, Dialéctica de la Dependencia, México, Era, 1973. Ver, también, Theotonio dos Santos, La Teoría de la Dependencia. Balance y Perspectivas, Buenos Aires, Plaza \& Janés, 2003; Agustín Cueva, Teoría social y procesos políticos en América Latina, México, Edicol, 1979, 15-39.
} 
problematizándolo, poniéndolo en discusión, en tanto formación compleja, contingente, conflictiva, que no puede ser desvinculada del proceso de expansión mundial capitalista ${ }^{12}$.

Ya en el campo de las relaciones internacionales, más allá de las diversas perspectivas e interpretaciones teóricas, prevalecen, en general, dos grandes tendencias al discutir integración regional, la liberal y la realista. En el contexto de la emergencia y consolidación del proceso europeo de integracionista, estas vertientes se constituyeron en las perspectivas más influyentes para la compresión de tal iniciativa colectiva, así como de las inéditas experiencias de integración en América Latina ${ }^{13}$. Dentro de las ramificaciones de la vertiente liberal encontramos perspectivas como la del funcionalismo (centrada en cómo la integración económica, personificada principalmente por agentes no gubernamentales, impulsarían la integración política, sin que ello signifique restarle importancia a los Estados nacionales ${ }^{14}$ ) o la del intergubernamentalismo liberal (que colocará énfasis en el comportamiento racional de los Estados para explicar la dinámica de la integración ${ }^{15}$ ). Ya en el caso de la vertiente realista, la integración regional respondería al interés nacional de supervivencia de los propios Estados, en un contexto internacional de disputas y anarquía ${ }^{16}$. Más allá de las diferencias entre todas estas perspectivas clásicas, lo que nos interesa destacar, en función de nuestro argumento, es que la integración regional es explicada en función de algún tipo de interés nacional, lo que, según lo observado por Kan y Pascual, remitiría casi siempre al fortalecimiento de las capacidades de eses Estados, entendidos de manera autocentrada ${ }^{17}$.

Si bien no se trata de negar que son los gobiernos, en representación del poder público, los titulares de la atribución de negociar e impulsar la política de integración con otros gobiernos, no podemos dejar de subrayar que ambas corrientes asumen el Estado como sujeto jurídico autónomo, como actor unitario, dejando de lado los procesos sociales contradictorios que subyacen a la formulación de tal política. Resultante de estos enfoques, que excluyen el conflicto de clases del campo interpretativo del regionalismo, encontramos un estudio de la integración en el que prevalece, en general, un análisis (a nivel de bloque, y de carácter normativista o prescriptivo) de instituciones, agenda, motivaciones y resultados (principalmente de orden económico-comercial), y donde la propia finalidad y fundamento de la integración de Estados es el fortalecimiento de sus capacidades (frente a otros Estados), en tanto ente autocentrado y formador del sistema interestatal.

También en el campo de las relaciones internacionales encontramos la llamada doctrina de la autonomía, corriente que, así como el estructuralismo cepalino en el debate económico latinoamericano, ha ocupado tradicionalmente un espacio en la reflexión propia, continental, sobre integración. En el intento de superación de la tradición realista clásica, y con base en las premisas cepalinas, la vertiente de la autonomía latinoamericana afirma que la periferia podría superar la situación de subdesarrollo y dependencia, contrarrestando el accionar hegemónico de los países centrales, a través de maniobras estratégicas de gobierno basadas en el interés nacional, orientadas a una inserción (autocentrada) más autónoma en el sistema internacional, considerando ciertas variables objetivas como movilización de recursos y compromiso de las élites política y económica (burguesía), principalmente ${ }^{18}$. Así, el problema

\footnotetext{
12 Fernando Henrique Cardoso y Enzo Faletto, "Post Scriptum a 'Dependencia y Desarrollo en América Latina”, Desarrollo Económico, 17:66, Buenos Aires, 1977, 273-299.

13 Andrés Malamud, "Latin American Regionalism and EU Studies", Journal of European Integration, 32:6, London, 2010, 637-657.

${ }^{14}$ Ernst Haas, Partidos políticos y grupos de presión en la integración europea. Análisis sociológico de experiencias históricas, Buenos Aires, Intal, 1966.

15 Andrew Moravcsik, "Preferences and Power in the European Community: A Liberal Intergovernamentalist Approach", Journal of Common Market Studies, 31:4, Cambridge, 1993, 473-524.

16 Hans Morgenthau, Política entre las naciones: la lucha por el poder y la paz, Buenos Aires, Grupo Editor Latinoamericano, 1986.

17 Julián Kan y Rodrigo Pascual, “Integración regional en América Latina y Argentina. ¿Solamente una cuestión de Estados?”, Alberto Bonnet (comp.), El país invisible. Debates sobre la Argentina reciente, Buenos Aires, Peña Lillo, Ediciones Continente, 2011, 45-79.

18 Juan Carlos Puig, Doctrinas internacionales y autonomía latinoamericana, Caracas, Universidad Simón Bolívar, 1980. Ver, también, Helio Jaguaribe, "Dependencia y Autonomía en América Latina", Helio Jaguaribe, Aldo Ferrer, Miguel Wionczek y Theotonio dos
} 
de esta vertiente se vincula con la presunción de que existiría en los países de la región una burguesía nacional (antimperialista) ${ }^{19}$, con genuino interés en el mercado doméstico y en el desarrollo económico nacional, que contribuiría con la "revolución capitalista" basada en la alianza entre capital y trabajo ${ }^{20}$.

En suma, sea para favorecer e impulsar el desarrollo interno y una inserción autónoma, sea para cumplir con las "exigencias" de liberalización comercial del sistema multilateral de comercio, la integración se presenta en estas perspectivas y abordajes como un instrumento de política estatal (instrumento que responde a un Estado neutro, en apariencia, y con fundamento en un supuesto interés nacional) en el ámbito del sistema capitalista, con claro predominio de la dimensión económico-comercial por sobre cualquier otra, principalmente de índole social, espejado en el modelo teleológico de la integración europea por "etapas”21.

\section{En defensa de una interpretación teórico-crítica alternativa del Mercosur}

En esta segunda parte del trabajo discutimos un abordaje de la integración que, por la vertiente teórica poulantziana en las que encuentra inspiración y sustento, llamará la atención acerca del conflicto social que subyace a esta política (conflicto, como ya dicho, relegado por las corrientes tradicionales). Al asumir al Estado como la forma política de la relación del capital (antagonismo entre capital y trabajo), afirmamos nuestro entendimiento acerca de la necesidad de contar con categorías analíticas para estudiar una política pública que, en tanto medida emanada del aparato estatal, está permeada por las contradicciones propias de la lucha de clases y de la correlación de fuerzas que se da en esa arena, en virtud de definiciones ideológicas, de capacidades y de alianzas.

En un país capitalista, las clases dominante (burguesía) y subalterna (popular) no están al margen de las decisiones del gobierno (aparato estatal), y en este sentido, la integración regional, como política pública, no es resultado apenas de acuerdos intergubernamentales, ni de la mera expansión de los mercados o de otras oportunidades sistémicas (factores externos), sino que es producto también de las categorías en disputa por las clases y fracciones de clase al interior de la estructura jurídico-institucional del Estado. En este sentido, estamos asumiendo que al análisis de los problemas o cuestiones identificados por las perspectivas tradicionales debemos incorporar las relaciones de clases y como éstas impactan en la configuración del tablero regional. Conforme afirmamos en un estudio anterior, "la identificación y análisis de los diferentes actores e intereses presentes en el proceso de diseño de la política estatal de integración se revela como una dimensión fundamental para su estudio y comprensión"22.

A la luz, entonces, de un enfoque que privilegie un abordaje de la integración desde la totalidad social de la cual emerge, buscamos discutir la trayectoria del Mercosur estableciendo relaciones, en el ámbito nacional, con las clases dominantes de Brasil y Argentina, particularmente con la llamada

Santos, La dependencia politico-económica de América Latina, Buenos Aires, Siglo Veintiuno, 1973, 1-85; Guillermo O’Donnell y Delfina Linck, Dependencia y Autonomía, Buenos Aires, Amorrortu, 1973.

19 José Briceño Ruiz y Alejandro Simonoff, "La Escuela de la Autonomía, América Latina y la Teoría de las Relaciones Internacionales", Estudios Internacionales, 49:186, Santiago, 2017, 39-89.

${ }^{20} \mathrm{El}$ término revolución capitalista es aquí utilizado en el sentido clásico de superación del capitalismo mercantil mediante la industrialización, o sea, de configuración de los pilares del desarrollo económico: acumulación capitalista con incorporación sistemática del progreso técnico. Celso Furtado, Desenvolvimento e Subdesenvolvimento, Rio de Janeiro, Editora Fundo de Cultura, 1961.

${ }^{21}$ Tradicionalmente, ha predominado en los estudios de nuestra región la perspectiva de asumir que la integración en estos sures debe responder al mismo trayecto llevado a cabo por la Unión Europea, razón ésta por la que en diversas ocasiones, por ejemplo, la falta de "éxito" del Mercosur ha sido adjudicado a la carencia de instituciones supranacionales, o circunscrito a los resultados alcanzados exclusivamente en materia de liberalización del comercio y perfeccionamiento de los requisitos para avanzar hacia el mercado común, conforme prescripto por la teoría de la integración económica clásica. Ver Béla Balassa, Teoría de la Integración Económica, México: Unión Tipográfica Editorial Hispano-Americana, 1961.

22 Leonardo Granato e Ian Batista Rebouças, "Estado, autonomia e integração regional na América Latina”, Latinoamérica: Revista de Estudios Latinoamericanos, 66, México, 2018, 261-285. 
burguesía interna, que al mismo tiempo que su dependencia con relación al capital extranjero la orienta a no apoyar proyectos de corte populista y antimperialista, precisa de medidas que protejan a la industria y al mercado interno. Retomando así la pregunta que inspira al presente trabajo, discutimos, en esta segunda parte del artículo, la idea de que los diferentes momentos o etapas atravesados por el Mercosur siempre correspondieron a los intereses de las burguesías internas de Brasil y Argentina, unificados bajo la hegemonía del capital financiero internacional y de las empresas transnacionales. Esta correspondencia es identificada, inclusive, en una coyuntura en que, ejercitándose una cierta autonomía relativa, los nuevos gobiernos progresistas de la región buscaron desafiar, a través de la acción política que significaba implementar un nuevo modelo integracionista, los cánones impuestos por la hegemonía del capital financiero internacional.

La génesis del Mercosur comenzó con la redemocratización de Argentina y Brasil a mediados de los años 80, de forma coincidente con el cierre del ciclo de crecimiento económico latinoamericano, con la crisis de la deuda externa y del modelo burocrático de Estado interventor y desarrollista. Con los objetivos principales de contribuir con el fortalecimiento de los procesos de redemocratización nacionales y afianzar la paz en la región, y basados en las tradicionales concepciones cepalina y autonomista ya abordadas, los gobiernos argentino y brasileño, con amplio apoyo de algunos sectores industriales locales, impulsaron, mediante el Programa de Cooperación e Integración Económica (1985-1988) y el Tratado de Integración, Cooperación y Desarrollo (1988), las bases para la creación paulatina de un mercado común, que contribuyese para el desarrollo interno de sus países -a través de protocolos sectoriales de coordinación interindustrial- y en la ampliación de los márgenes de autonomía en la arena internacional ${ }^{23}$.

Hacia inicios de la década de ' 90 , los condicionamientos económicos por los que pasaron ambos países, en un contexto de reestructuración y ofensiva capitalista, abrieron una ventana de oportunidades para que los nuevos gobiernos neoliberales, que asumieron en ambos países, reorientaron el esquema de integración inter-industrial hacia el objetivo de liberalización comercial total, en consonancia con las directrices para la construcción del Estado neoliberal en América Latina ${ }^{24}$. Con la suscripción del Tratado de Asunción en marzo de 1991, se pondría fin a la etapa iniciada en 1985, que proyectaba una integración gradual, equilibrada, flexible y simétrica ${ }^{25}$, y se pasaría a un programa de desgravación progresiva, lineal y automática para todo el universo arancelario, poniendo fin a los últimos resquicios de la estrategia de desarrollo hacia adentro basada en la sustitución de importaciones.

El desmantelamiento de las barreras comerciales pasó a ser el objetivo central del proceso de integración, sustituyendo la dinámica de los protocolos sectoriales que enfatizaban la integración interindustrial de la etapa anterior ${ }^{26}$. A partir de ese momento, el objetivo de la integración sería utilizar el mercado común para potencializar las ventajas comparativas, convirtiéndolo en la plataforma de inserción (subalterna) de los países miembros en el orden económico internacional27; así el modelo desarrollista de la integración fue substituido por la integración "abierta" a los mercados, colocando a la promoción del comercio y de las inversiones extranjeras como el eje dinámico del proceso con una estructura institucional mínima, funcional al mencionado eje ${ }^{28}$.

\footnotetext{
${ }^{23}$ Leonardo Granato, Brasil, Argentina e os rumos da integração: o Mercosul e a Unasul, Curitiba, Appris, 2015.

${ }^{24}$ John Williamson (ed.), Latin American Adjustment: How Much Has Happened?, Washington, Institute for International Economics, 1990.

25 Roberto Lavagna, Argentina - Brasil - Mercosur: Una decisión estratégica 1986-2001, Buenos Aires, Ciudad Argentina, $1998,99$.

${ }^{26} \mathrm{El}$ argumento de que la apertura comercial promovería, por sí misma, el desarrollo económico fue uno de los pilares del Mercosur, lo que demuestra el carácter comercialista de la concepción de integración que subyacía al bloque.

27 Mario Rapoport, Historia económica, política y social de la Argentina (1880-2000), Buenos Aires, Ediciones Macchi, 2000. Ver, también, Aldo Ferrer, Hechos y ficciones de la globalización: Argentina y el Mercosur en el sistema internacional, Buenos Aires, Fondo de Cultura Económica, 2006.

28 Estas características formaban parte de lo que, en 1994, la CEPAL definió como lo que debería ser la nueva estrategia de integración en América Latina, el regionalismo abierto, modelo este que buscó consagrar la idea de una integración al servicio de la liberalización comercial y de inserción de los países latinoamericanos en las cadenas globales productivas. CEPAL, "El
} 
La impronta neoliberal también se reflejó en la estructura institucional mínima adoptada por el Mercosur (antes y después del Protocolo de Ouro Preto de 1994, que estableció la estructura definitiva) centralizada en los poderes ejecutivos ${ }^{29}$, con énfasis en la eficiencia en la administración y ejecución del Tratado de Asunción, y con bajo costo para Estados partes. El carácter intergubernamental de la arquitectura institucional definitiva aprobada en Ouro Preto encontró fundamentos no sólo en el espíritu eminentemente comercial del emprendimiento regional, sino también en el ideario organizacional hegemónico en ese momento, el gerencialismo, adoptado por las administraciones públicas de los Estados partes en aras de sustituir los tradicionales métodos de la organización burocrática del Estado por las técnicas y valores del mercado o de la gestión de negocios.

Se instaló así, según Katz, bajo el auspicio de funcionarios públicos, empresas multinacionales y capitalistas sudamericanos (aliados al gran capital financiero internacional), el llamado "Mercosur de los negocios," en que las principales beneficiadas por la ampliación de escala de los mercados y las reducciones aduaneras fueron las grandes corporaciones transnacionales establecidas en Brasil y Argentina ${ }^{30}$. Ya en el caso de las burguesías internas, subordinadas a las compradoras, vieron al Mercosur como una oportunidad para el aumento de sus exportaciones de productos manufacturados ${ }^{31}$, lo que también significaba una compensación por las pérdidas derivadas de la liberalización comercial. Fue en ese contexto que las elites políticas, en articulación con los sectores hegemónicos del capital extranjero, pasaron a invertir, "desde arriba" 32 , en la consolidación del Mercosur como una etapa preparatoria para el ingreso de la subregión al Área de Libre Comercio de las Américas (ALCA), propuesta norteamericana de integración hemisférica, que se proponía reducir los costos de producción interna a través de la conocida agenda de integración competitiva. Pero la postura intransigente del gobierno norteamericano en las negociaciones, así como los impactos regresivos del modelo neoliberal que no tardarían en hacerse sentir en la región como un todo, sentaron las bases, a fines de la década de los '90 para las demandas populares por un nuevo modelo de integración, así como para el rechazo del mencionado proyecto imperialista, rechazo este que se cristalizaría en 2005 con la acción coordinada de los países del bloque mercosureño.

A partir de los años 2000, en el contexto de la crisis de la hegemonía neoliberal, de una coyuntura favorable de crecimiento de la economía mundial, y de fuertes protestas y movilizaciones sociales, una nueva ola de gobiernos progresistas de la región fue expresión de una alteración en la correlación de fuerzas al interior de los Estados. En líneas generales, a pesar de la diversidad de las experiencias históricas de los varios países, podemos afirmar que los nuevos gobiernos buscaron márgenes para la superación del dogma neoliberal a través del intento de reconfiguración de los pactos nacionales entre capital y trabajo. De esta forma, sin deshacer las principales directrices de política económica de los gobiernos neoliberales (comprometiéndose, de hecho, la definición de formulaciones más profundas sobre cuestiones más estructurales), los gobiernos progresistas afirmaron la necesidad de implementación de agendas nacionales y sociales de desarrollo, en diálogo con las camadas populares de la sociedad. La política de integración sudamericana pasaría a ser para estos gobiernos, y en particular para los de Lula da Silva en Brasil y Kirchner en Argentina, una prioridad de la política exterior reorientada por los vectores de autonomía externa y desarrollo interno ${ }^{33}$.

regionalismo abierto en América Latina y el Caribe. La integración económica en servicio de la transformación productiva con equidad", Documento Institucional, Santiago, CEPAL, 1994.

29 Particularmente en los primeros mandatarios, encargados de la conducción política del bloque, y en los ministros de economía y de relaciones exteriores, que integraban el órgano ejecutivo del Mercosur.

${ }^{30}$ Claudio Katz, El rediseño de América Latina: ALCA, MERCOSUR y ALBA, Buenos Aires, Ediciones Luxemburg, 2006.

31 En su estudio, Bouzas destaca el aumento exponencial de los flujos de comercio intra y extrazona, así como de las corrientes de inversiones extranjeras, ocurrido en el bloque entre 1994 y 1998. Roberto Bouzas, "El MERCOSUR diez años después. ¿Proceso de aprendizaje o déjà vu?”, Desarrollo Económico, 41:162, Buenos Aires, 2001, 179-200.

32 Expresión utilizada por Kan en su obra. Julián Kan, La integración desde arriba. Los empresarios argentinos frente al MERCOSUR y el ALCA, Buenos Aires, Imago Mundi, CICCUS, 2015.

33 Granato, op. cit. 
En este nuevo escenario, con expresivo apoyo de movimientos y organizaciones de la sociedad civil, el Mercosur buscaría ser reconfigurado a través de la inclusión de nuevas temáticas de corte político, social y productivo en la agenda interna del bloque, pero sin conseguir alterar, en esencia, el carácter mercantil y dependiente del bloque, en términos de inserción externa, carácter este funcional, como ya fuera mencionado, a garantizar el statu quo de ciertos sectores de las burguesías dominantes en Brasil y Argentina, aglutinados bajo la hegemonía del gran capital financiero internacional. Ya en el caso particular de las burguesías internas de ambos países, el apoyo a la integración del Mercosur puede ser explicada, así como en los orígenes, en virtud de las ventajas económicas derivadas del comercio intra-bloque. En el caso brasileño, la burguesía interna ${ }^{34}$ que se fue fortaleciendo desde los años 2000 y que desempeñó un relevante papel en el rechazo del país al ALCA, mantuvo, durante el gobierno de Lula ${ }^{35}$, una postura pragmática frente al Mercosur, el cual debería permanecer restricto a su dimensión económicocomercial $^{36}$. En este sentido, conforme las evidencias discutidas en un trabajo anterior, resultaría posible afirmar que la dimensión política así como otras medidas de política pública destinadas a profundizar la integración más allá de la esfera económica nunca formaron parte de la agenda estratégica para el Mercosur de esta fracción de la burguesía interna brasileña ${ }^{37}$. En el caso de la burguesía interna argentina ${ }^{38}$, tal como afirmado por Schorr y Wainer, la actuación de la misma con relación al Mercosur se habría estructurado en torno de la crítica a la política brasileña de apoyo al sector privado productivo, y del objetivo de fortalecer la protección de la industria nacional frente a las importaciones del país vecino (principalmente en materia de calzado, textil y electrodomésticos), sin una preocupación que apuntara a la redefinición del perfil de las exportaciones y a una reindustrialización sobre la base de nuevas capacidades productivas ${ }^{39}$. En este sentido, la apuesta de esta fracción de la burguesía no iba más allá que en reducir al Mercosur a un espacio de libre circulación de capitales y mercancías. De esta forma, pese a los intentos de cambio de la época impulsados por los gobiernos de Lula y Kirchner ${ }^{40} \mathrm{con}$ expresivo apoyo de las organizaciones y movimientos sociales, orientados a profundizar las dimensiones política y social de la integración regional, parece haber continuado prevaleciendo en el Mercosur, entre 2003 y 2016, la lógica y valores de mercado, lógica y valores que lo marcaron desde su origen.

Con base en el entendimiento precedente, discutamos algunas evidencias en materia de agenda interna del bloque ${ }^{41}$. En términos de integración productiva, pese a la aprobación, en 2008, del Programa de Integración Productiva del Mercosur, y en 2012, del Mecanismo de Fortalecimiento Productivo del Mercosur, la articulación de políticas industriales comunes con vistas al desarrollo armónico y sustentable de la subregión, desafiantes del tradicional modelo de dependencia de los países centrales, nunca dejó de ser un tema pendiente. Conforme afirmado por Katz:

\footnotetext{
${ }^{34}$ La gran burguesía interna se encuentra integrada por diversos sectores económicos, tales como industria, minería, construcción pesada y agroindustria.

35 Armando Boito Jr., "A burguesia no governo Lula", Crítica Marxista, 21, São Paulo, 2005, 52-77. Ver, también, Armando Boito Jr. y Tatiana Berringer, "Brasil: Classes sociais, neodesenvolvimentismo e política externa nos Governos Lula e Dilma", Revista de Sociologia e Politica, 21:47, Curitiba, 31-38, 2013.

36 Tatiana Berringer, "A burguesia interna brasileira e a integração regional da América do Sul (1991-2016)", Oikos, 16:1, Rio de Janeiro, 2017, 15-29.

${ }^{37}$ Leonardo Granato e Ian Rebouças Batista, "Intereses en pugna en el estado brasileño en torno de la política de integración para el Mercosur (2003-2010)", Relaciones Internacionales, 38, Madrid, 2018, 41-57.

38 Integran esta fracción sectores exportadores cuyas actividades se caracterizan en general por funciones de producción de naturaleza capital-intensiva, tales como agroindustria, petróleo y derivados y algunos commodities industriales.

39 Martín Schorr y Andrés Wainer, "A propósito de la crisis del Mercosur. Notas sobre el proyecto de país de la 'burguesía nacional' en la Argentina”, Realidad Económica, 215, Buenos Aires, 2005, 11.

40 Uno de los documentos oficiales que sienta las bases esenciales para esta nueva concepción del Mercosur es el llamado Consenso de Buenos Aires, suscripto por los presidentes Lula da Silva y Kirchner en 2003.

${ }^{41}$ No haremos mención en este trabajo de importantes iniciativas tales como el Instituto Social del Mercosur, el Instituto de Políticas Públicas en Derechos Humanos del Mercosur o el Sector Educativo del MERCOSUR, espacio de coordinación de las políticas educativas que reúne los países miembros del bloque.
} 
la asociación no ha concretado ningún paso hacia la coordinación macroeconómica. El divorcio de monedas, tipos de cambios y políticas fiscales entre sus integrantes es mayúsculo (...), y como la industria retrocede, tampoco hay planes de coordinación fabril o utilización compartida de la renta exportadora ${ }^{42}$.

Asimismo, este cuadro se vio reforzado por relevantes cuestiones en discusión de la agenda externa del Mercosur, tales como las negociaciones con la Unión Europea, con China y los embates sufridos por la apuesta de algunos países de la región en el Acuerdo Transpacífico y otros acuerdos bilaterales de libre comercio. Estas evidencias refuerzan la insistencia de las burguesías de ambos países, con una lógica de acumulación crecientemente transnacional, en mantener una inserción subordinada en el escenario internacional, en actividades de bajo dinamismo y valor agregado.

En términos institucionales, buena parte del diseño institucional del Mercosur siguió asociado a la racionalidad aperturista propia de los años '90, y esferas como el PARLASUR43 o la Unidad de Participación Social, creadas como forma de ampliación de la base de sustentación social del proceso de integración, se revelaron bastantes limitadas. Finalmente, en términos de tratamiento de las grandes asimetrías y desigualdades nacionales y sociales dentro de cada país, y del bloque de integración como un todo, la agenda relacionada con el FOCEM 44 (puesto en marcha en 2007) estuvo, en el período, mayormente determinada por cuestiones coyunturales, que por una estrategia sostenible de largo plazo para reducir disparidades. Asimismo, la ausencia de esta estrategia de largo plazo se articula también con el peso relativo de los fondos.

En líneas generales, es posible afirmar que la retórica política que auspiciaba un nuevo Mercosur presentó resultados limitados en la práctica. Al hacer referencia a la "utopía" del llamado "Mercosur Social y Productivo" que caracterizó esta etapa, Porta afirmó:

aquella utopía (un deseo no necesariamente concretado) está arrinconada, asustada y, finalmente, trabada por el 'fantasma' del Mercosur comercial; la transición entre una fase y otra ha resultado ser bastante más complicada de lo que inicialmente parecía y, en particular, de lo que la sintonía y afinidad política de los gobiernos del Mercosur en los últimos años parecía preanunciar ${ }^{45}$.

Según Fuser, los gobiernos progresistas fueron incapaces de superar la inserción subalterna defendida por sus burguesías internas, así como de garantizar condiciones efectivas para la consolidación del nuevo modelo de integración propuesto ${ }^{46}$. La opción estratégica de esta fracción de clase, en desmedro de cualquier proyecto estatal autónomo de desarrollo interno inclusivo, siempre fue la asociación con el capital financiero internacional, consintiendo la integración subordinada de los sectores productivos a las cadenas productivas globales ${ }^{47}$, o simplemente "cadenas de valor", lo que cristaliza, a todas luces, la persistencia de las condiciones estructurales que históricamente reproducen la dependencia regional.

42 Claudio Katz, "Economía, clases y gobiernos en América Latina", Revista de Estudos e Pesquisas sobre as Américas, 8:2, Brasília, $2014,112$.

43 Acrónimo de Parlamento del Mercosur.

44 Acrónimo de Fondo para la Convergencia Estructural del Mercosur.

${ }^{45}$ Fernando Porta, "La utopía del 'MERCOSUR social y productivo' y el fantasma del 'MERCOSUR comercial”, Daniel García Delgado y Cristina Ruiz del Ferrier (comps.), Estado y desarrollo inclusivo en la multipolaridad: desafíos y políticas públicas, Buenos Aires, FLACSO, 2015, 105.

46 Igor Fuser, "Reflexões sobre as burguesias sul-americanas e a integração regional", Estudos Internacionais, 5:3, Belo Horizonte, 2017, 112-125.

47 Una interesante discusión sobre este concepto, que hace referencia a la estrategia global de segmentación productiva adoptada por las compañías transnacionales, puede ser encontrada en: Mariano Treacy, "Discusiones sobre autonomía en la recepción de los aportes dependentistas al campo de las Relaciones Internacionales y contribuciones recientes desde el enfoque de Cadenas Globales de Valor", Revista Aportes para la Integración Latinoamericana, 38, La Plata, 2018, $45-67$. 


\title{
Conclusiones
}

Tal como propuesto, a la luz de una crítica a los abordajes hegemónicos en materia de integración regional, buscamos reflexionar sobre la trayectoria del Mercosur, argumentando acerca de la correspondencia de tal trayectoria con los intereses de las burguesías internas de Argentina y Brasil. En la primera parte del artículo fueron discutidas las perspectivas dominantes de los pensamientos económico y de relaciones internacionales, resaltando como la integración era pensada a partir de un concepto liberal de Estado. Ya en la segunda parte, a partir de la noción de Estado propuesta por Poulantzas en su crítica al Estado capitalista, discutimos cómo el Mercosur "pos-liberal" no refleja otra cosa que la consagración de los intereses de las burguesías internas de Brasil y Argentina.

Tal como quedó evidenciado a partir de la discusión propuesta, lejos de haber significado una ruptura con relación al modelo neoliberal anterior, el nuevo modelo integracionista del Mercosur de los gobiernos progresistas (esencialmente político y con fuerte contenido de articulación de políticas públicas) no se mostró desafiante del modelo de inserción subalterna conveniente a las fracciones hegemónicas de las burguesías internas de los mayores países del bloque, aliadas al capital financiero internacional. Una integración política que promoviese autonomía y desarrollo interno parece nunca haber integrado el horizonte estratégico de tales fracciones de clase que, bajo la lógica capitalista de lucro, supieron enfrentar los intentos autonomistas de la integración política del período progresista en la región.

Dicho en otras palabras, el Mercosur siempre ha presentado una regularidad, independientemente de la concepción de intervención del Estado en la economía: la de ser una estrategia de las burguesías y aparatos estatales cooperando en torno de una política común, en mayor o menor medida, según el período histórico, pero siempre limitada y subordinada a los ciclos de acumulación del capital, no constituyendo en modo alguno, intentos de alternativizar la hegemonía del capital. Tal vez estas líneas nos ayuden a pensar en las limitaciones de cualquier interpretación en el campo de la integración que aspire a emancipar la lucha política de toda determinación estructural. De forma más general, creemos estar abriendo futuras líneas de investigación que profundicen la discusión acerca de las limitaciones objetivas que los regímenes de acumulación y la correlación de fuerzas imponen, en este campo de la integración en particular, a la acción política.

\author{
Bibliografia
}

Fuentes impresas

- Agustín Cueva, Teoría social y procesos políticos en América Latina, México, Edicol, 1979.

- Aldo Ferrer, Hechos y ficciones de la globalización: Argentina y el Mercosur en el sistema internacional, Buenos Aires, Fondo de Cultura Económica, 2006.

- Andrew Moravcsik, "Preferences and Power in the European Community: A Liberal Intergovernamentalist Approach", Journal of Common Market Studies, 31:4, Cambridge, 1993, 473-524.

- Armando Boito Jr. y Tatiana Berringer, "Brasil: Classes sociais, neodesenvolvimentismo e política externa nos Governos Lula e Dilma", Revista de Sociologia e Politica, 21:47, Curitiba, 31-38, 2013.

- Armando Boito Jr., “A burguesia no governo Lula”, Crítica Marxista, 21, São Paulo, 2005, 52-77.

- Béla Balassa, Teoría de la Integración Económica, México: Unión Tipográfica Editorial HispanoAmericana, 1961. 
- Celso Furtado, Desenvolvimento e Subdesenvolvimento, Rio de Janeiro, Editora Fundo de Cultura, 1961.

- Claudio Katz, El rediseño de América Latina: ALCA, MERCOSUR y ALBA, Buenos Aires, Ediciones Luxemburg, 2006.

- Ernst Haas, Partidos políticos y grupos de presión en la integración europea. Análisis sociológico de experiencias históricas, Buenos Aires, Intal, 1966.

- Fernando Porta, "La utopía del 'MERCOSUR social y productivo' y el fantasma del 'MERCOSUR comercial”", Daniel García Delgado y Cristina Ruiz del Ferrier (comps.), Estado y desarrollo inclusivo en la multipolaridad: desafios y políticas públicas, Buenos Aires, FLACSO, 2015, 105-111.

- Guillermo O'Donnell y Delfina Linck, Dependencia y Autonomía, Buenos Aires, Amorrortu, 1973.

- Hans Morgenthau, Política entre las naciones: la lucha por el poder y la paz, Buenos Aires, Grupo Editor Latinoamericano, 1986.

- Helio Jaguaribe, "Dependencia y Autonomía en América Latina", Helio Jaguaribe, Aldo Ferrer, Miguel Wionczek y Theotonio dos Santos, La dependencia político-económica de América Latina, Buenos Aires, Siglo Veintiuno, 1973, 1-85.

- John Williamson (ed.), Latin American Adjustment: How Much Has Happened?, Washington, Institute for International Economics, 1990.

- Juan Archibaldo Lanús, La integración económica de América Latina, Buenos Aires, Juárez Editor, 1972.

- Juan Carlos Puig, Doctrinas internacionales y autonomía latinoamericana, Caracas, Universidad Simón Bolívar, 1980.

- Julián Kan y Rodrigo Pascual, "Integración regional en América Latina y Argentina. ¿Solamente una cuestión de Estados?”, Alberto Bonnet (comp.), Elpaís invisible. Debates sobre la Argentina reciente, Buenos Aires, Peña Lillo, Ediciones Continente, 2011, 45-79.

- Julián Kan, La integración desde arriba. Los empresarios argentinos frente al MERCOSUR y el ALCA, Buenos Aires, Imago Mundi, CICCUS, 2015.

- Leonardo Granato, Brasil, Argentina e os rumos da integração: o Mercosul e a Unasul, Curitiba, Appris, 2015.

- Mario Rapoport, Historia económica, politica y social de la Argentina (1880-2000), Buenos Aires, Ediciones Macchi, 2000.

- Martín Schorr y Andrés Wainer, "A propósito de la crisis del Mercosur. Notas sobre el proyecto de país de la 'burguesía nacional' en la Argentina”, Realidad Económica, 215, Buenos Aires, 2005, 8-19.

- Nicos Poulantzas, A crise das ditaduras: Portugal, Espanha e Grécia, Rio de Janeiro, Paz e Terra, 1976.

- Nicos Poulantzas, O Estado, o poder e o socialismo, Rio de Janeiro, Graal, 1980.

- Nicos Poulantzas, Poder político e classes sociais, São Paulo, Martins Fontes, 1977.

- Roberto Bouzas, "El MERCOSUR diez años después. ¿Proceso de aprendizaje o déjà vu?”, Desarrollo Económico, 41:162, Buenos Aires, 2001, 179-200.

- Roberto Lavagna, Argentina - Brasil - Mercosur: Una decisión estratégica 1986-2001, Buenos Aires, Ciudad Argentina, 1998.

- Ruy Mauro Marini, Dialéctica de la Dependencia, México, Era, 1973.

- Theotonio dos Santos, La Teoría de la Dependencia. Balance y Perspectivas, Buenos Aires, Plaza \& Janés, 2003. 
Fuentes electrónicas o digitalizadas

- Andrés Malamud, "Latin American Regionalism and EU Studies", Journal of European Integration, 32:6, London, 2010, 637-657. Disponible en https://www.tandfonline.com/doi/abs/10.1080/07036337.2010.518720 (obtenido el 12 de febrero de 2019).

- CEPAL, "El regionalismo abierto en América Latina y el Caribe. La integración económica en servicio de la transformación productiva con equidad", Documento Institucional, Santiago, CEPAL, 1994. Disponible en https://www.cepal.org/es/publicaciones/2140regionalismo-abierto-america-latina-caribe-la-integracion-economica-al-servicio (obtenido el 12 de febrero de 2019).

- Claudio Katz, "Economía, clases y gobiernos en América Latina”, Revista de Estudos e Pesquisas sobre as Américas, 8:2, Brasília, 2014, 92-123. Disponible en http://periodicos.unb.br/index.php/repam/article/view/12613 (obtenido el 2 de diciembre de 2018).

- Fabricio Pereira da Silva, "La bajada de la marea rosa en América Latina. Una introducción", Revista de la Red Intercátedras de Historia de América Latina Contemporánea-Segunda Época, 5:8, Córdoba, 2018, 59-66. Disponible en https://revistas.unc.edu.ar/index.php/RIHALC/article/view/20459/20074 (obtenido el 2 de diciembre de 2018).

- Igor Fuser, "Reflexões sobre as burguesias sul-americanas e a integração regional", Estudos Internacionais, 5:3, Belo Horizonte, 2017, 112-125. Disponible em http://periodicos.pucminas.br/index.php/estudosinternacionais/article/view/15326 (obtenido el 2 de diciembre de 2018).

- José Briceño Ruiz y Alejandro Simonoff, "La Escuela de la Autonomía, América Latina y la Teoría de las Relaciones Internacionales", Estudios Internacionales, 49:186, Santiago, 2017, 3989. Disponible en https://revistaei.uchile.cl/index.php/REI/article/view/45218 (obtenido el 2 de diciembre de 2018).

- José Luís Fiori, "Estado e desenvolvimento na América Latina: notas para um novo "programa de pesquisa", Documento de Trabalho, 286, Brasília, CEPAL Escritório no Brasil, 2013, 1-15. Disponible en https://repositorio.cepal.org/bitstream/handle/11362/37942/1/LCbrsR286_pt.pdf (obtenido el 2 de diciembre de 2018).

- Leonardo Granato e Ian Batista Rebouças, "Estado, autonomia e integração regional na América Latina", Latinoamérica: Revista de Estudios Latinoamericanos, 66, México, 2018, 261-285. Disponible en http://www.revistadeestlat.unam.mx/index.php/latino/article/view/56962 (obtenido el 2 de diciembre de 2018).

- Leonardo Granato e Ian Rebouças Batista, "Intereses en pugna en el estado brasileño en torno de la política de integración para el Mercosur (2003-2010)", Relaciones Internacionales, 38, Madrid, 2018, 41-57. Disponible en https://revistas.uam.es/index.php/relacionesinternacionales/article/view/8791 (obtenido el 13 de febrero de 2019).

- Mariano Treacy, "Discusiones sobre autonomía en la recepción de los aportes dependentistas al campo de las Relaciones Internacionales y contribuciones recientes desde el enfoque de Cadenas Globales de Valor", Revista Aportes para la Integración Latinoamericana, 38, La Plata, 2018, 45-67. Disponible en 
https://revistas.unlp.edu.ar/aportes/article/download/5614/4610/ (obtenido el 2 de diciembre de 2018).

- Raúl Prebisch, "El desarrollo económico de América Latina y sus principales problemas. 1948", Documento Institucional, Santiago, CEPAL, 2012. Disponible en https://repositorio.cepal.org/bitstream/handle/11362/40010/4/prebisch_desarrollo_prob lemas.pdf (obtenido el 12 de febrero de 2019).

- Tatiana Berringer, "A burguesia interna brasileira e a integração regional da América do Sul (1991-2016)", Oikos, 16:1, Rio de Janeiro, 2017, 15-29. Disponible en http://www.revistaoikos.org/seer/index.php/oikos/article/viewArticle/439 (obtenido el 13 de febrero de 2019). 